\title{
The Study of Position Performance Appraisal Based on Total Relationship Flow Management Theorems
}

\author{
Ganggang Yin \\ School of Management, Jinan University, Guangzhou, China \\ Email: 1357307113@qq.com
}

Received 30 May 2016; accepted 25 June 2016; published 28 June 2016

Copyright (C) 2016 by author and Scientific Research Publishing Inc.

This work is licensed under the Creative Commons Attribution International License (CC BY).

http://creativecommons.org/licenses/by/4.0/

c) (i) Open Access

\begin{abstract}
Total Relationship Flow Management Theorems(TRFMTs) show that for an organization, its behavior $H_{o r}(t)$ is determined and governed only by its input flow $R f(t)$ and relationship flow set $R f_{\text {ord }}(t)$ at its basic level $H d$, i.e. the total relationship flow $T R f(t)=R f(t) \cup R f_{\text {ord }}(t)$. This means that the performance of an organization is not decided by the departments or the positions, but by all kinds of its relationship flows including information flows, matter flows, energy flows, fund flows, personnel flows, etc. Therefore, the assessment of organizational performance should focus on the relationship flows between positions of an organization. In this paper, we study the issue of position performance appraisal on the view of TRFMTs. With the production line positions as an example, we design a system of position performance appraisal based on TRFMTs. Firstly, the system is more suitable for production line positions, which improves the efficiency of position performance assessment. Moreover, it provides a theoretical foundation for organizational behavior and performance appraisal to guide organization to strengthen the management of total relationship flows and develops management to become an exact science.
\end{abstract}

\section{Keywords}

Organization Design and Management, Position, Performance Appraisal, Total Relationship Flow Management Theorems (TRFMTs)

\section{Introduction}

All activities of the organization are to pursue the performance. Performance appraisal, as a management tool, has been a hot topic in the field of staff research. However, the results of performance appraisal are not always

How to cite this paper: Yin, G.G. (2016) The Study of Position Performance Appraisal Based on Total Relationship Flow Management Theorems. Journal of Human Resource and Sustainability Studies, 4, 110-116. 
satisfying. In recent years, researchers have tried to improve the effectiveness of performance appraisal from various angles.

According to TRFMTs, the performance of the organization is not decided by the departments or the positions, but by all kinds of relationship flows including information flows, matter flows, energy flows, fund flows, personnel flows, etc. [1]. Therefore, the assessment of organizational performance should focus on the relationship flows between positions of the organization.

On this basis, we propose a position performance appraisal system based on TRFMTs. Combining TRFMTs to position performance appraisal, this study provides a novel approach of organization performance evaluation and develops management to become an exact science.

\section{Research Status}

\subsection{Performance Appraisal}

More than a century, performance appraisal has formed a relatively complete methodology, which can be divided into three categories: behavior-oriented, results-oriented, strategic-oriented, including: ranking, alternating sort, paired comparison method, forced distribution rating, rating scales, critical incident technique, graphic rating scale, management by objectives, 360 degree, key performance indicators, balanced score card and the like.

In recent years, the researchers pay attention to optimizing the existing assessment methods of performance appraisal to solve the problem that performance appraisal is not very effective in practice. Those studies can be summarized as the following three forms:

(1) Factors that affect the performance appraisal: analyzed the internal and external factors that influence organizational performance evaluation by empirical methods, researchers put forward specific proposals.

For example, using establishment data from the Australian Workplace Industrial Relations Survey, Michelle Brown \& John S. Heywood estimated the determinants of performance appraisal systems, indicating that performance appraisal is associated with workers having shorter expected tenure and greater influence over productivity, and complementary human resource management practices, such as formal training and incentive pay, are associated with an increased likelihood of performance appraisal, but that union density is associated with a reduced likelihood of performance appraisal [2].

(2) Technical methods of performance evaluation: better algorithms and models are used to replace the existing assessment methods to obtain a more objective and fair performance appraisal result.

In the reference [3], the fuzzy c-means (FCM) clustering algorithm is applied to employee performance appraisal, which selects the most appropriate employee(s) and clusters them with respect to the evaluation. Compared FCM with the current system, Coskun Ozkan concludes that, in performance appraisal systems, FCM is more flexible and satisfactory compared to conventional method.

(3) Analyzed and classified the Objective of performance evaluation: according to different purposes of performance appraisal, adopt different assessment methods.

Herbert H. Meyer argues that the purposes of performance appraisal are different, so we should adopt a different way of assessment. Performance evaluation for administrative decisions (such as merit pay, promotion, etc.) should be separated from those for staff development or to communicate with staff [4].

Thus, we can see that scholars are gradually considering organizational performance evaluation on a specific implementation environment, looking for better performance evaluation method; In terms of job performance evaluation, depending on the evaluation subjects and organization types, researchers trend to choose different evaluation methods, which indicates performance evaluation is developed towards a more detailed and precise direction.

\subsection{Total Relationship Flow Management Theorems (TRFMTs)}

Applying the structural theory of general systems in management, Professor Lin. F. proposed Total Relationship Flow Management Theorems (TRFMTs), which is a new cross-cutting areas of scientific research [5]. It shows that the behavior of an organization is determined and governed only by its input flow $R f(t)$ and relationship flow set $R f_{\text {ord }}(t)$ at its basic level $H d$, i.e. the total relationship flow $T R f(t)=R f(t) \cup R f_{\text {Ord }}(t)$ [1]. In a word, understanding and controlling the organizational behavior is to understand and control the flows of their overall 
relationship in the final analysis. The research of TRFMTs is to finding the ideas, theories, methods, means and tools of TRFMTs, which will help us to understand and control the total relationship flows of systems better, then to control the organization behavior effectively.

Currently, TRFMTs is mainly applied in organizational design, organizational management, networks, information systems management, channel design, job analysis, etc. [5]-[11].

\section{The Position Performance Appraisal System Based on TRFMTs}

TRFMTs argues that the assessment of organizational performance should focus on the relationship flows between positions; TRFMMs also shows that for any relationship flow $R f_{i j}(t)$ of an organization, such as information flow or fund flow, a tiny change at time $t$ may exert a prodigious influence on the behavior $H_{O r}(t)$ of the organization. Therefore, it needs the output of precise relationship flows between positions in precise time to obtain the expected behaviors of the organization. In order to meet the precise position output, we first need to clear the flows that the position sends to upstream post, e.g. orders for materials, are proper or not. Generally speaking, position performance is determined by the following two parts: (1) the position outputs the precise relationship flows in precise time or not; (2) the flows that position sends to upstream post are precise or not.

In this article, we assume that there is already an organization that was designed based on the TRFMTs; Moreover, the organization values the management of the relationship flows between the positions, and position evaluation is based on the relationship flows.

For simplicity, we takes a Production and Sales divisions of a certain manufacturing for example, highlighting the performance evaluation system in production line positions. JIT production system is utilized in this organization, in that sales department is responsible for receiving customer orders and sales while production department produces products. The operation logic of production and sales is shown in Figure 1:

Operation logic between the organization positions is following, as shown in Figure 2.

(1) Through internal information systems, the production planning is sent to position A. To finish the production planning, downstream posts issue orders to A, including the time of receipt, the type of raw material, raw material quantity and quality requirements; then A receives the orders at time $t$.

(2) According to the position material consumption standard, position A sends material orders to its upstream posts.

(3) In accordance with the requirements of position A, upstream posts complete the semi-finished production and output to A within the stipulated time.

(4) Based on orders and standards, A checks and receives the semi-finished productions, makes the evaluation to its upstream, and inputs evaluation results to organization assessment system.

(5) Following the order that downstream posts required, A completes the semi-finished production and outputs to downstream positions within the stipulated time.

(6) Based on orders and standards, downstream positions check and receive the semi-finished productions, makes the evaluation to $\mathrm{A}$, and inputs evaluation results to organization assessment system.

(7) Repeat from (1) to (6).

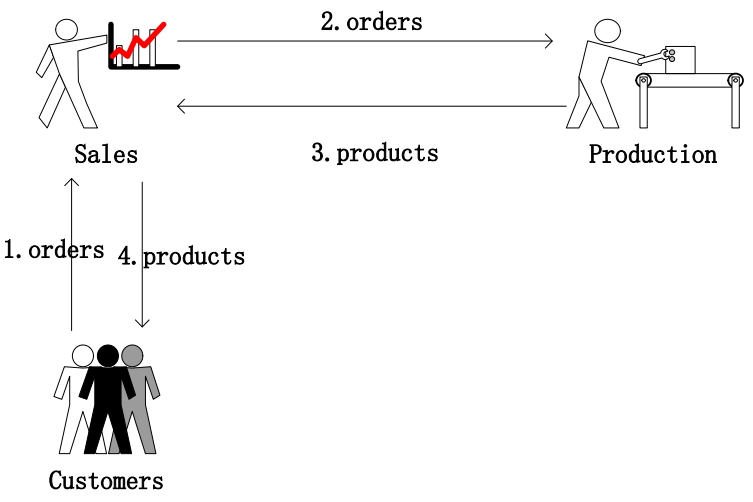

Figure 1. The operation logic of production and sales. 


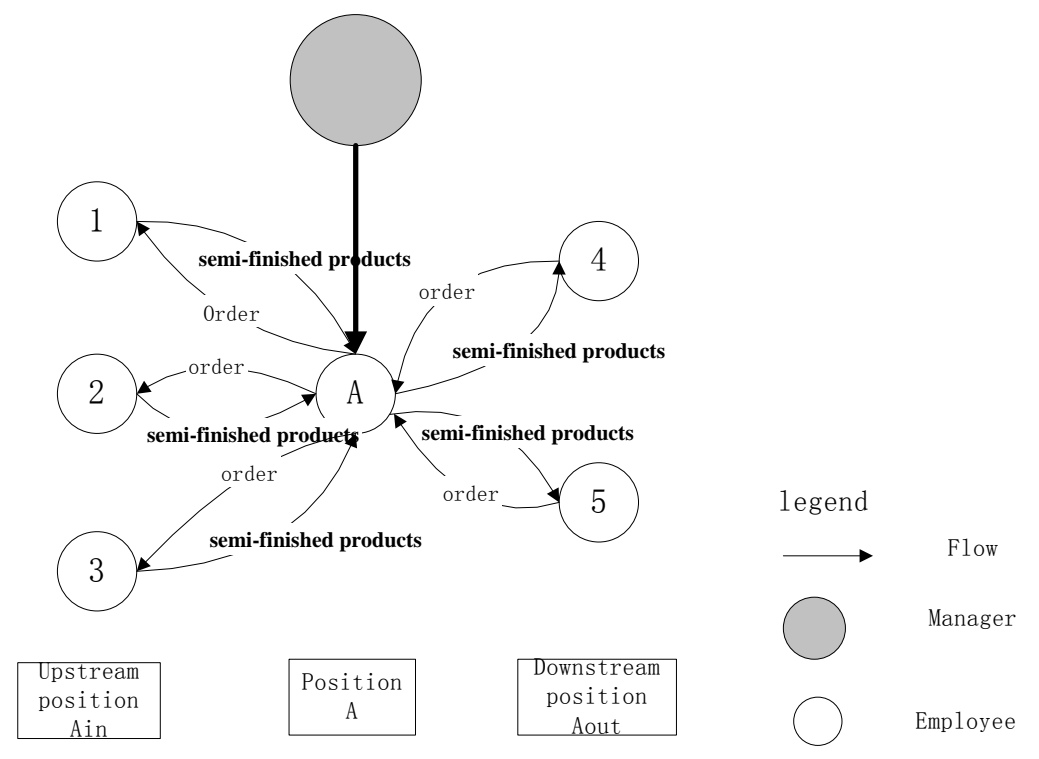

Figure 2. Operation logic between the organization positions.

\subsection{The Logic of Position Performance Appraisal}

What to be assessed: organization checks whether the positions output the precise relationship flows. In order to meet the precise position output, we first need to clear the flows that the position sends to upstream post ,e.g. orders for materials, are proper or not. Generally speaking, position performance is determined by the following two parts: (1) the position outputs the precise relationship flows in precise time or not; (2) the flows that position sends to upstream post are precise or not.

How to assess: upstream positions output the expected semi-finished products to its downstream positions. As long as their outputs are praise in terms of specie, quantity, quality, and time, the positions will get great performance evaluation. Similarly, if the outputs did not do well or not completely well, bad performance evaluation is obtained. If an error occurs, and the adjacent positions pass the buck to each other, performance appraisal department checks the transmitted order information. If the order information is not proper, the position is assumed to be responsible for the error, otherwise the upstream post will take for it.

Who to assess: the system of position performance appraisal consists of position A, the downstream posts of $\mathrm{A}$, and performance appraisal department.

Downstream position is responsible for reviewing the relationship flows that posts output, while performance appraisal department examines the flows positions send to their upstream position.

\subsection{Design for the Position Performance Appraisal System Based on TRFMTs}

According to the analysis above, we define three parts for the position performance appraisal system based on TRFMTs, that are (1) performance appraisal department (2) assessment process (3) assessment indicators and the right weight.

\subsubsection{Performance Appraisal Department}

In this article, we name it as "performance appraisal committee"; it can be acted by the position in HR division in practice.

Main duties of performance appraisal committee are as follows:

(1) Guarantee the normal operation of position performance appraisal system;

(2) According to the standards, train employees to use position performance appraisal system correctly;

(3) Arbitrate liability disputes between positions;

(4) Following the management information service, organize the evaluation that downstream posts assessed to position A;

(5) Examine the relationship flows that positions send to their upstream positions; 
(6) Form the assessment scale for position A by data (4) and (5);

(7) Offer feedback of the assessment scales to HR (Employee payroll, training, and promotion are partly based on them).

\subsubsection{Assessment Process}

(1) In accordance with the order requirements, position A outputs the expected semi-finished products to its downstream positions in the stipulated time;

(2) Based on the evaluation standards, upstream posts evaluate A, and input evaluation to MIS;

(3) Performance appraisal committee regularly assess material orders that position A sent to its upstream;

(4) Performance appraisal committee organize the evaluation that downstream posts assessed to position A;

(5) Performance appraisal committee form the assessment scale for position A by data (3) and (4);

(6) The performance appraisal scales will be sent to the HR to complete the position performance appraisal.

\subsubsection{Assessment Indicators and the Right Weights}

As previously described, the performance of position A is determined by the following two parts: (1) position A outputs the precise relationship flows in precise time or not; (2) the flows that position A sends to upstream posts are precise or not. According to TRFMTs, we set up each assessment indicators respectively.

Firstly, position A outputs the precise relationship flows in precise time.

In line with TRFMTs, the following four performance indicators were decided to measure the outputs of A, i.e. precise species, precise quantity, precise quality, precise time.

Here we define and refine the " 4 precise".

(1) "precise species", that is appropriate product category, is measured by "actual product category" and "expected product category" are the same. When $\mathrm{T}_{\mathrm{A}} \mathrm{AP}=\mathrm{T}_{\text {Aout }} \mathrm{EP}$, denoted as $\mu=1$, otherwise $\mu=0$.

Where TAAP represents "actual product categories" that position A provided, and $\mathrm{T}_{\text {Aout }} \mathrm{EP}$ means “expected product category” by downstream jobs.

(2) "precise time", is measured by the ratio "actual operating time" and "expected completion time", denoted as $\mathrm{T}_{\mathrm{A}} \mathrm{AF} / \mathrm{T}_{\mathrm{Aout}} \mathrm{EF}=\alpha$. When $\alpha=1$, the actual operating time is equal to the expected completion time; when $\alpha>$ 1 , the actual operation time is longer than the expected completion time; when $\alpha<1$, the actual operation time is less than the expected completion time.

Where $\mathrm{T}_{\mathrm{A}} \mathrm{AF}$ and $\mathrm{T}_{\text {Aout }} \mathrm{EF}$ indicate the "actual operating time" and the "expected completion time", respectively.

(3) "precise quantity": the "actual quantity of products" divided by the" expected quantity of products" is used to weigh for it, referred to as $\mathrm{T}_{\mathrm{A}} \mathrm{AQ} / \mathrm{T}_{\mathrm{Aout}} \mathrm{EQ}=\beta$. When $\beta=1$, the number of productions supplied by posts is equal to the desired quantity; When $\beta>1$, the actual number is greater than the expected number; When $\beta<1$, the actual number is less than the expected number.

Where $\mathrm{T}_{\mathrm{A}} \mathrm{AQ}$ and $\mathrm{T}_{\text {Aout }} \mathrm{EQ}$ indicate the "actual quantity of products" and "the expected quantity of products", respectively.

(4) "precise quality": it is measured by the "actual product mass" divided by the "expected product mass", denoted as $\mathrm{T}_{\mathrm{A}} \mathrm{AM} / \mathrm{T}_{\text {Aout }} \mathrm{EM}=\theta$. When $\theta=1$, the actual product quality meets the expectations of quality. When $\theta>1$, the actual product quality is better than expected quality (in practice, we encourage such a case, but it generally does not occur.); When $\theta<1$, the actual product quality is inferior to the desired product quality.

Where $\mathrm{T}_{\mathrm{A}} \mathrm{AM}$ represents the "actual mass"of products supplied by post A, and $\mathrm{T}_{\text {Aout }} \mathrm{EM}$ means the "expected mass” of products.

Therefore, the outputs performance of position $\mathrm{A}$ is a function of these four indicators. The outputs performance of position $\mathrm{A}, \mathrm{P}_{\mathrm{A}}=f$ (actual product category/expected product category, actual operating time/expected completion time, actual quantity of products/expected quantity of products, the actual mass of products/the expected mass of products), i.e. $\mathrm{P}_{\mathrm{A}}=f(\mu, \alpha, \beta, \theta)$.

How to identify and calculate $\mu, \alpha, \beta, \theta$ will be described in subsequent studies.

Secondly, that the flows that position A sends to upstream post are precise or not, are lied on two aspects: a. the transmission time of the order is appropriate, a delay or not; b. order information relating to products (or raw materials) is accurate or not, including the content (species of raw materials), quantity, expected completion time. It means that "the praise time to send order "and "appropriate order information" determine the praise relation- 
ship flows that position A sends to upstream posts.

(a) The transmission time of the order is appropriate, a delay or not.

After receiving the orders from the downstream positions, it takes some time to determine the species and quantity of raw materials and production time, and then issues the materials information to the upstream positions. There is a certain time lag, recorded as the necessary delay time. Organization clears the necessary delay time of each position. Therefore, performance appraisal committee checks the delay time to judge the transmission time of the order is proper or not, which is as follows.

The time that position A sends orders to the upstream positions $\left(t_{2}\right)$ - the time that position A receives the orders from downstream positions $\left(t_{1}\right) \leq$ the necessary delay time $(r)$, that is $t_{2}-t_{1} \leq r$.

b. Order information relating to products (or raw materials) is accurate or not, including the content (species of raw materials), quantity, expected completion time.

Are the product categories appropriate? Performance appraisal committee judges those by viewing the customer orders.

About expected quantity of products, positions A must meet predetermined internal loss standard $\left(T_{A} Q\right)$, namely $\mathrm{T}_{\mathrm{A}} \mathrm{QE} \leq \mathrm{T}_{\mathrm{A}} \mathrm{Q}$.

Expected completion time should meet organizational standards.

The product quality that position A expects, meet but not more than the specified quality standards.

Described above, the system of Position Performance Appraisal Based on TRFMTs, can be summarized by Figure 3.

\section{Conclusions}

TRFMTs researches the relationship between the environment, organizational structure and behavior, abstracts an organization to the set of relationship flows between the positions, and proves that organizational behavior $H_{O r}(t)$ is determined and governed only by its input flow $R f(t)$ and relationship flow set $R f_{\text {ord }}(t)$ at its basic level $H_{d}$. From the perspective of TRFMTs, this article studies the position performance appraisal. Taking the production line positions as an example, we firstly analysis the logic of position performance appraisal system, including operation logic between the organization positions and the logic of position performance appraisal; then design the appraisal system, expounding the performance appraisal department, assessment process, and assessment indicators, forming the conceptual model of organization position performance appraisal.

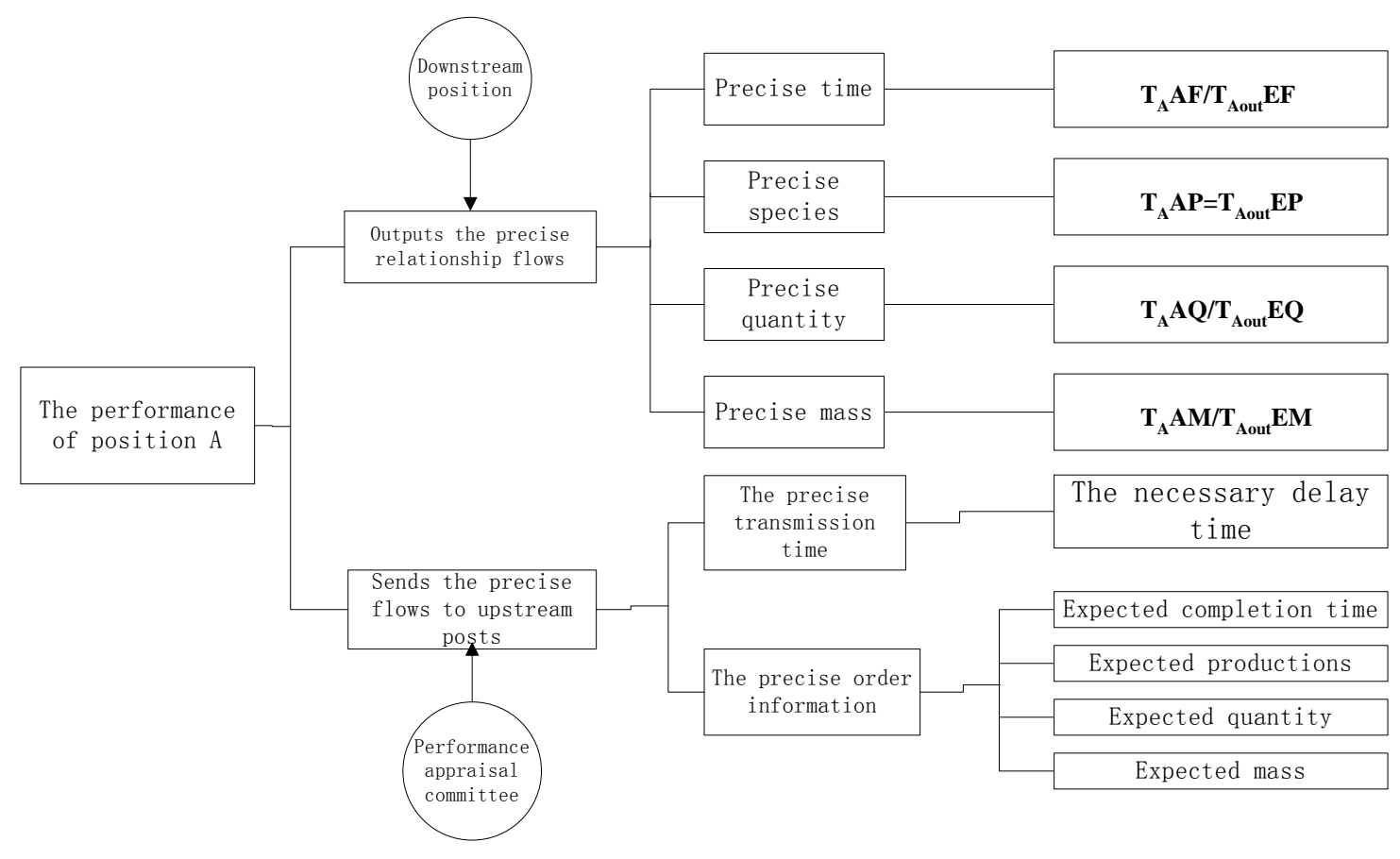

Figure 3. Position performance appraisal based on TRFMTs. 
TRFMTs is a new management concept and idea, reflecting the optimization of behavior and relationship flows in the organization. In this paper, we design a performance appraisal system for production line positions, and clearly indicate position performance determined by output flows and flows sent to upstream posts, and precise flows are to produce high-performance. For managers and researchers, this paper aims to provide a new perspective for performance appraisal, and brings some enlightenment on the optimization of the organizational structure. It extends the vision and idea of the existing performance appraisal study and develops management to become an exact science.

Shortcomings are as follows:

(1) This article only presents the conceptual model of organization position performance appraisal, but does not introduces parameter calculation method.

(2) Taking the production line positions as an example, it is representative, but lacks of universality.

(3) In management practice, just designing and optimizing the model are not enough, combining the actual situation and using flexibility are the key.

For the above shortcomings, further research will focus on the following improvements: the weight of evaluation index will be determined by Analytic Hierarchy Process (AHP), and clear the formula of position performance; analyze the characteristics of different positions, then improve the model, making it fits for the evaluation of the different types of jobs. In addition, it is desirable to introduce a business case in future research. Combining with the actual internal and external environment, implement the TRFMTs to apply the position performance appraisal system flexibly in practice.

\section{References}

[1] Lin, F. and Cheng, T.C.E. (2007) The Structural Theory of General Systems Applied in Management: The Total Relationship Flow Management Theorems. International Journal of General Systems, 36, 673-681. http://dx.doi.org/10.1080/03081070701265216

[2] Brown, M. and Heywood, J.S. (2005) Performance Appraisal Systems: Determinants and Change. British Journal of Industrial Relations, 43, 659-679.

[3] Ozkana, A., et al. (2014) Variant Perspective to Performance Appraisal System: Fuzzy C-Means Algorithm. International Journal of Industrial Engineering, 21, 168-178.

[4] Meyer, H.H. (1991) A Solution to the Performance Appraisal Feedback Enigma. Executive, 5, 68-76.

[5] Lin. F. and Cheng, T.C.E. (2013) Developing an Organization Design Framework Based on the Total Relationship Flow Management Theorems. IEEE Transactions on Systems, Man, and Cybernetics: System, 43, 1466-1476.

[6] Chen, Z.M. (2009) The Model of Management Information System Based on System Dynamics. Jinan University, Guangzhou.

[7] Jiang, W.L. (2011) The Design of Distribution Channels Based on the Total Relationship Flow Management Theorems-A Case Study on X Company. Jinan University, Guangzhou.

[8] Luo, J.T. (2013) Modeling and Simulation of Organizational Structure Based on Total Relationship Flow Management Theorems. Jinan University, Guangzhou.

[9] Zeng, X.J. (2013) The Analysis and Design of Marketing Knowledge Management System Based on the Total Relationship Flow Management Theorems. Jinan University, Guangzhou.

[10] Hu, F.L. (2015) The Design of Human Resource Recruitment System Based on the Total Relationship Flow Management Theorems-A Case Study of X Company. Jinan University, Guangzhou.

[11] Liu, Z.M. (2015) Job Design Framework Based on the Total Relationship Flow. Jinan University, Guangzhou. 